

\title{
Metal nanoparticles for the catalytic synthesis of carbon nanotubes
}

Christophe Laurent, Emmanuel Flahaut, Alain Peigney, Abel Rousset

\section{To cite this version:}

Christophe Laurent, Emmanuel Flahaut, Alain Peigney, Abel Rousset. Metal nanoparticles for the catalytic synthesis of carbon nanotubes. New Journal of Chemistry, 1998, vol. 22 (n $\left.\mathrm{n}^{\circ} 11\right)$, pp. 12291237. 10.1039/a801991f . hal-01104345

\section{HAL Id: hal-01104345 \\ https://hal.science/hal-01104345}

Submitted on 16 Jan 2015

HAL is a multi-disciplinary open access archive for the deposit and dissemination of scientific research documents, whether they are published or not. The documents may come from teaching and research institutions in France or abroad, or from public or private research centers.
L'archive ouverte pluridisciplinaire HAL, est destinée au dépôt et à la diffusion de documents scientifiques de niveau recherche, publiés ou non, émanant des établissements d'enseignement et de recherche français ou étrangers, des laboratoires publics ou privés. 


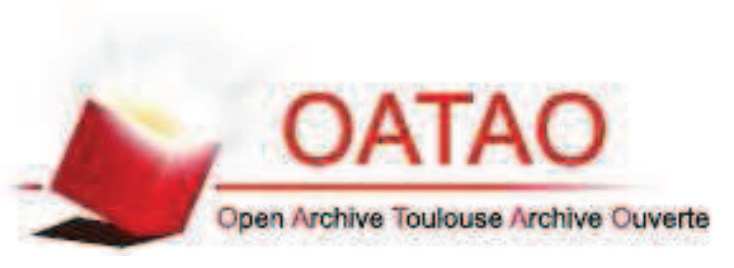

\section{Open Archive Toulouse Archive Ouverte (OATAO)}

OATAO is an open access repository that collects the work of Toulouse researchers and makes it freely available over the web where possible.

This is an author-deposited version published in: http://oatao.univ-toulouse.fr/ Eprints ID: 11053

To link to this article : DOI:10.1039/a801991f

URL: http://dx.doi.org/10.1039/a801991f

\section{To cite this version:}

Laurent, Christophe and Flahaut, Emmanuel and Peigney, Alain and Rousset, Abel Metal nanoparticles for the catalytic synthesis of carbon nanotubes. (1998) New Journal of Chemistry, vol. 22 ( $\left.\mathrm{n}^{\circ} 11\right)$. pp. 1229-1237. ISSN 1144-0546 


\title{
Metal nanoparticles for the catalytic synthesis of carbon nanotubes
}

\author{
Christophe Laurent, * Emmanuel Flahaut, Alain Peigney and Abel Rousset \\ Laboratoire de Chimie des Marériaux Inorganiques, (CNRS ESA 5070), Université \\ Paul-Sabatier, 31062 Toulouse cedex 4, France
}

\begin{abstract}
Single-wall and multiwall carbon nanotubes are currently the subject of an intense research effort owing to the outstanding properties they may possess. Many synthesis methods have been proposed, most of which involve nanometric metal particles. In this article the various mechanisms proposed for nanotube nucleation and growth from such particles have been reviewed. The micro/nanostructure of the materials obtained by the different methods have also been addressed.
\end{abstract}

To the question 'What exactly is a carbon nanotube?', Ebbesen proposed in an early review ${ }^{1}$ of this fast evolving field the answer that it is 'a fullerene, a fibre, a micro-crystal, a tube ... perhaps a little bit of each and more'. Indeed, carbon nanotubes are at the intersection of the science of carbon fibres, a well-established domain, and the relatively novel field of fullerenes (Kroto, Smalley and Curl, Nobel Prize for Chemistry 1996).

Hollow carbon fibres have been observed for several decades, but it is the groundbreaking report by Iijima ${ }^{2}$ on the obtaining of carbon tubes with a diameter in the nanometer range, the so-called carbon nanotubes, and on their relation to the recently discovered fullerenes, ${ }^{3}$ that triggered a worldwide research effort devoted to improving their synthesis, to determining their structure ${ }^{4-8}$ and to calculating and measuring their physical properties. ${ }^{9-18}$ Most of the early theoretical work has focused on single-wall tubes (denoted as SWT hereafter) and the actual measurement of the properties of such minute objects has proven to be a challenging task.

A comprehensive description of the structure, properties and applications of carbon nanotubes is given in the book by Dresselhaus et al., ${ }^{19}$ to which the reader is referred for more details. SWT, cylindrical in shape, are considered to be either infinite or to have caps at each end, such that the two caps can be joined to form a fullerene. The cylindrical portion of the tube consists of a single graphene sheet, rolled to form a cylinder. Bisecting a $\mathrm{C}_{60}$ molecule normal to a fivefold or a threefold axis and inserting a cylinder, one obtains the socalled 'armchair' or 'zigzag' tubes, respectively. Such tubes present no helicity. However, there are various possible caps and different ways to roll the sheet, each way corresponding to a particular tube diameter and helicity. ${ }^{2} \mathrm{~A}$ helical vector represented by a pair of integers $(n, m)$ has also been defined. The minimum capped tube diameter that has been observed is $0.71 \mathrm{~nm}$, which is equal to that of the $\mathrm{C}_{60}$ molecule. The corresponding helical vectors are $(5,5)$ for the 'armchair' tube and $(9,0)$ or $(0,9)$ for the 'zigzag' tube. A transmission electron microscopy (TEM) image showing single-wall carbon nanotubes is shown in Fig. 1(a). Most often, multiwall nanotubes (denoted as MWT in the following), consisting of several coaxial carbon cylinders, are observed [Fig. 1(b)]. The measured interlayer distance $(0.34 \mathrm{~nm})$ is very close to that measured between graphene sheets in graphite. There appears to be no particular correlation between the helicity of concentric layers. ${ }^{1,2}$

A particularly interesting feature is the possibility of filling or covering the tubes with other materials. Tsang et al. ${ }^{20}$ and

*E-mail: laurent@iris.ups.tlse.fr
Ajayan et al. ${ }^{21}$ have found that heating carbon nanotubes in an oxidizing atmosphere results in attack on the pentagons in the fullerene cap and thus in tube opening. Oxidation in the presence of $\mathrm{Pb}$ resulted in the filling of the tubes by a $\mathrm{Pb}$ compound $^{22}$ due to a nanocapillarity process. Other chemical methods have been proposed. ${ }^{23}$ The in situ formation of nanotubes filled with a metalloid, a metal or a carbide (the socalled nanowires) was also investigated. ${ }^{24-28}$ In addition, several groups ${ }^{29-32}$ have used the nanotubes as templates to prepare tubular oxides.

(a)

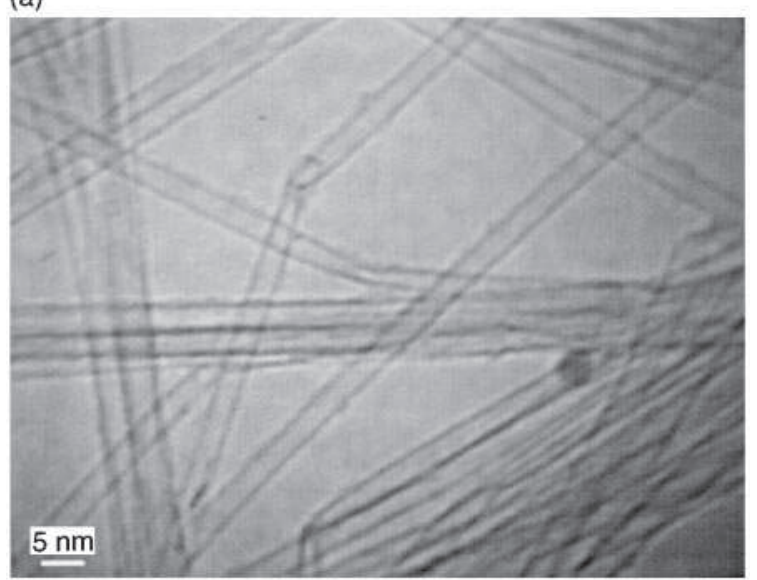

(b)

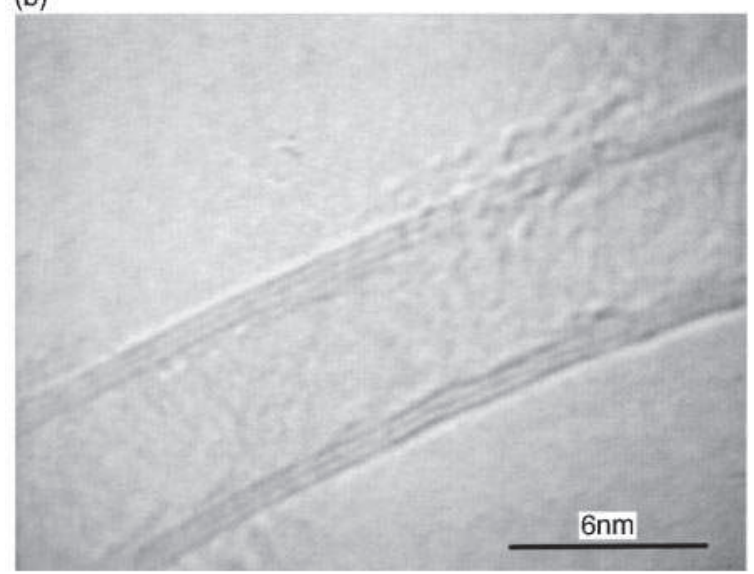

Fig. 1 Transmission electron microscopy image showing single-wall carbon nanotubes either isolated or in bundles (a) and showing a threewall carbon nanotube (b); these tubes have been prepared by the catalysis method in the present authors' laboratory (see text for details) 
Both theoretical and experimental studies ${ }^{33-38}$ have shown that carbon nanotubes have excellent mechanical characteristics. Indeed, the Young's modulus of MWT has been calculated ${ }^{36}$ to be up to 1.4 times that of a graphite whisker (i.e., about $1 \mathrm{TPa}$ ) and values derived from thermal vibration experiments performed on several MWT in a transmission electron microscope ${ }^{38}$ are in the $0.4-3.7 \mathrm{TPa}$ range. Moreover, the flexibility of carbon nanotubes is remarkable ${ }^{39,40}$ and the bending may be fully reversible up to a critical angle value as large as $110^{\circ}$ for SWT. ${ }^{37}$ The electrical characteristics of the nanotubes have also been investigated by theoretical and experimental works, ${ }^{9-13,41-43}$ which have brought to light some remarkable features that could be related to the unique one-dimensional nature of the tubes. Depending on structural parameters such as the tube diameter and helicity, either a metallic or semi-conducting behaviour may be observed.

Obviously, a possible application of the nanotubes could be as part of new composite materials that may exhibit outstanding properties. Several groups $s^{34,35,44-52}$ are working on the preparation of materials containing carbon nanotubes, which, besides their specific properties, are considered as the ultimate carbon fibres. ${ }^{33}$

Many methods have been used to produce carbon nanotubes but they mainly fall into one of the following categories: arc discharge in the absence or presence of metal, laser vaporization of a metal-graphite composite target, carbon monoxide disproportionation on a metal catalyst and hydrocarbon pyrolysis, generally using a metal catalyst. In the following sections, we will review the different synthesis methods of Iijima-type carbon nanotubes and the nucleation and growth mechanisms that have been proposed. Although emphasis will be placed on those that involve nanometric metal particles, mechanisms that do not will also be mentioned. The micro/nanostructure of the obtained tubes and materials will be addressed and will be illustrated by examples from the present authors' work.

\section{Arc-discharge and laser Vaporisation Methods}

\section{Arc-discharge methods}

The arc-discharge method for the preparation of carbon nanotubes is similar to that used for the synthesis of fullerenes. Following the initial report of Iijima, ${ }^{2}$ Ebbesen and Ajayan ${ }^{53}$ have proposed modifications for the large-scale synthesis of carbon nanotubes. An inert gas atmosphere (typically $\mathrm{He}$ ) is flowed through a reaction vessel at a controlled pressure. Two graphite rods constitute the electrodes, between which a potential difference is applied. As the rods are brought close together, a discharge occurs resulting in the formation of a plasma. A deposit, which may contain carbon nanotubes under certain conditions, forms on the larger negative electrode (cathode) while the smaller positive electrode (anode) is consumed. When a metal catalyst is to be used, a hole is drilled in the carbon anode and it is filled with a mixture of metal and graphite powder. In this case, most nanotubes are found in the soot deposited on the arc-chamber wall. ${ }^{54}$ Typically, the outer diameter of carbon nanotubes prepared by the arc-discharge method ranges between 2 and $20 \mathrm{~nm}$ and the inner diameter ranges between 1 and $3 \mathrm{~nm} .{ }^{1}$ The length is micrometric. It is important to note that the obtained materials do not consist solely of nanotubes but also of nontubular forms of carbon such as nanoparticles, fullerenes and a lot of amorphous carbon. Ebbesen et al. ${ }^{44}$ have reported that oxidation of the deposit eliminates all nanoparticles and nanotube caps so that open tubes can be obtained free of other carbon species. However, only $c a .1 \mathrm{wt} \%$ of the initial deposit remains after oxidation.
In the absence of metal catalyst, several authors ${ }^{55,56}$ have proposed a growth mechanism based on the incorporation of carbon dimers into a cagelike precursor. The tubes grow from an empty fullerene cage by repeated additions of $\mathrm{C}_{2}$ to a hemispherical cap. Lengthening of the tubes results from rearranging the carbon bonds to incorporate additional $\mathrm{C}_{2}$ near a pentagonal ring. Since the growing tube is always closed, there is no mechanism to enclose materials into it. Other researchers ${ }^{57-60}$ have proposed that the tubes are open during the growth process and that carbon atoms $\left(\mathrm{C}_{1}, \mathrm{C}_{2}, \mathrm{C}_{3}\right)$ are adsorbed at the active dangling bond edge sites. Iijima et $a l .{ }^{57,58}$ suggested that the extension and thickening of the tubes occur by the island growth of graphene basal planes on existing tube surfaces. In the case of SWT, these authors assume that axial growth predominates over layer growth. Dresselhaus et al. ${ }^{19}$ point out that since the experimental conditions for forming carbon nanotubes vary significantly depending on growth method, more than one mechanism may be operative.

Iijima and Ichihashi ${ }^{58}$ have prepared SWT by covaporizing graphite and $\mathrm{Fe}$ in an $\mathrm{Ar}-\mathrm{CH}_{4}$ atmosphere. The tube diameters are in the $0.7-1.6 \mathrm{~nm}$ range with peaks in the distribution at around 0.8 and $1.05 \mathrm{~nm}$. The SWT often form bundles. These authors noticed that no tubes were formed when the carbon arc reactor was operated with any one of the three components ( $\mathrm{Ar}, \mathrm{CH}_{4}$ and $\mathrm{Fe}$ ) absent. Cementite particles ranging in size from a few nanometers to several tens of nanometers and coated with a few graphite layers were observed, but no $\mathrm{Fe}$ or $\mathrm{Fe}$ carbide particles were found at the tips of the tubes. It was, however, assumed that Fe particles acting as a homogeneous catalyst in the gas phase somehow assist in the formation of SWT.

Bethune et $a l .{ }^{61}$ have reported that covaporizing carbon and $\mathrm{Co}$ in an arc generator under a $\mathrm{He}$ atmosphere leads to the formation of carbon SWT of very small diameter ( $c a .1 .2$ $\mathrm{nm})$. These authors stress that the tubes grow from carbon vapor with no dissociation of hydrocarbon needed. Co is found in the form of round clusters with diameters ranging from an few nanometers to $20 \mathrm{~nm}$. However, the relationship between the Co particles and the tubes remained unclear. Under the same experimental conditions, no tube growth was observed when using $\mathrm{Fe}, \mathrm{Ni}$ or a $50: 50 \mathrm{Ni}-\mathrm{Cu}$ mixture, in contrast to results obtained in the presence of hot gaseous hydrocarbons. ${ }^{62,63}$ The same group of authors has reviewed the field of SWT ${ }^{54}$ at the time (1995) and they pointed out that how the metal exerts its catalytic influence remained an open question. Available results suggested a model where small catalytic particles rapidly assemble in a region of high carbon density. SWT nucleate and grow very rapidly on these particles as soon as they reach a critical size, leading to the relatively narrow diameter distributions observed.

In the presence of a Co-based catalyst, the promoters $\mathrm{S}, \mathrm{Bi}$ and $\mathrm{Pb}$ have been found to increase the production yield of SWT as well as dramatically modify the diameter distribution. ${ }^{64}$ According to Kiang and Goddard, ${ }^{64}$ the differences in structure and growth environments suggest that the SWT growth mechanism is distinct from that of multilayer nanotubes or carbon fibres. These authors have proposed that planar polyyne rings serve as nuclei for the formation of SWT, whose diameter would be related to the ring size (Fig. 2). Thus $\mathrm{C}_{32}$ and $\mathrm{C}_{38}$ monocyclic rings would lead to SWT with diameters of 1.25 and $1.5 \mathrm{~nm}$, respectively, which correspond to the peaks in the measured diameter distribution. The starting materials for producing SWT are monocyclic carbon rings, acting as nanotube precursors, and $\mathrm{Co}_{m} \mathrm{C}_{n}$ species, acting as catalysts. The composition and structure of the Co carbide cluster are undetermined, but it should be able to bond to $\mathrm{C}_{n}$ and/or to add the $\mathrm{C}_{n}$ to the growing tube. In the arc plasma, the presence of electrons and other charged species (carbon and metal clusters) may cause the geometry of a monocyclic 
(a)

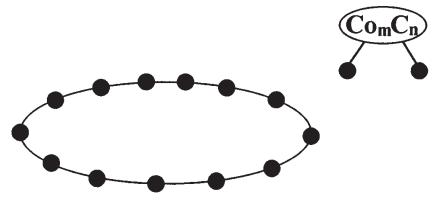

(b)
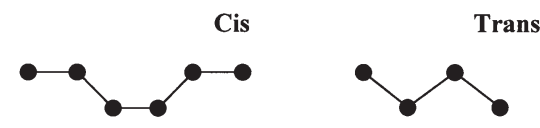

(c)

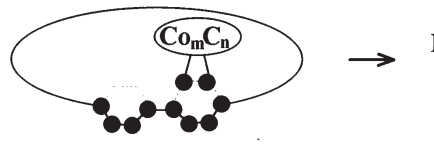

Non-helical tube (armchair)

(d)

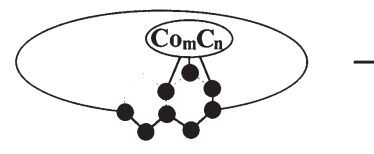

Non-helical tube (zigzag)

(e)

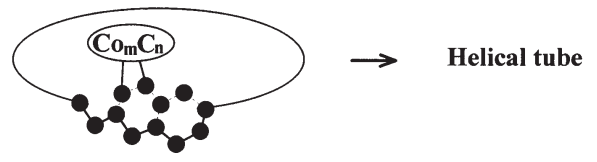

Fig. 2 Diagrams illustrating the polyyne ring nucleation mechanism for the growth of carbon SWT: $(a)$ a monocyclic polyyne ring is the precursor and a Co carbide cluster is the catalyst; $(b)$ deformation of the monocyclic ring from its planar geometry due to charges or catalyst, resulting in local cis and trans forms; $(c)$ formation of a nonhelical tube having the armchair structure; $(d)$ formation of a non-helical tube having the zigzag structure; $(e)$ formation of a helical tube; after the first benzene rings are formed at a cis site, growth continues on trans sites to generate tubes with a helical structure; other helical growth patterns are possible (adapted from Fig. 2 in ref. 64)

ring to deviate from the uniform planar form at elevated temperatures, resulting in local cis or trans carbon deformations. The helical angles of the tubes are determined by the ratio of cis to trans conformations of the nucleus ring during the growth of the first benzene ring belt. The authors ${ }^{64}$ claim that the observed lack of additional layers on the catalytically produced nanotubes supports the hypothesis that the nanotubes grow from a polyyne ring gas phase species (because there are no nuclei to form multiple layers), in contrast to multiwalled tubes that grow from the cathode, which provides a surface for the nucleation of multiple layers. Furthermore, this model with open-end growth is consistent with the observations that amorphous material can be included in the tube, in contrast to closed-end mechanisms. ${ }^{55,56}$ The formation of larger tubes upon the addition of $\mathrm{S}, \mathrm{Bi}$ or $\mathrm{Pb}$ to the Co catalyst suggests that these promoters modify the growth at the nucleation stage; they may stabilize larger monocyclic rings, providing the nuclei necessary to build larger diameter SWT.

Recently, Journet et al. ${ }^{65}$ have reported the large-scale production of SWT by the electric-arc technique. These authors emphasize that their results are very similar to those of Thess et al. ${ }^{66}$ (yields in the $70-90 \%$ range, diameters around $1.4 \mathrm{~nm}$, crystalline bundles of a few tens of tubes and only a few isolated SWT). They point out that this therefore implies that there is a unique growth mechanism for the nanotubes, which does not strongly depend on the details of the experimental conditions, but which depends much more on the kinetics of carbon condensation in a non-equilibrium situation. Temperature and temperature gradients in space and time must play an important role, as can be seen by the fact that most of the SWT were found in a very specific zone of the reactor (a few centimeters around the cathode). In addition, these authors claim that the use of a second element (Y) beside the $\mathrm{Ni}$ or Co catalyst during the evaporation process strongly favours the SWT growth.

Iijima and Ichihashi ${ }^{58}$ have claimed that $\mathrm{Ar}, \mathrm{Fe}$ and $\mathrm{CH}_{4}$ are the three indispensable materials to produce SWT and Bethune $e t a l .{ }^{61}$ reported that no tube growth was observed when using $\mathrm{Ni}$ as catalyst. In contrast, a study by Saito et al. ${ }^{67}$ revealed that $\mathrm{Ni}$ is also an effective catalyst for the production of SWT and that the addition of $\mathrm{CH}_{4}$ to the arc reactor is not at all necessary. Regarding the influence of $\mathrm{Ni}$, Saito et al. ${ }^{68,69}$ pointed out that no Ni clusters or particles are observed at the tips of the tubes, but they reported that the SWT grow radially from a Ni carbide particle (Fig. 3). Similar results have been reported using $\mathrm{La}^{70} \mathrm{Gd}^{71}$ and $\mathrm{Y},{ }^{72}$ but the tube length is much shorter (ca.100 nm) in these cases than when using Ni (a few micrometers). The tube diameter is also larger. These authors ${ }^{68,69}$ have proposed a growth process of SWT from a core metal particle. When a metal catalyst is evaporated together with carbon by arc discharge, carbon and metal atoms condense and form alloy particles. As the particles are cooled, carbon dissolved in the particles segregates onto the surface because the solubility of carbon decreases with decreasing temperature. Some singular surface structures or compositions on an atomic scale may catalyse the formation of SWT. After the tube nuclei are formed, carbon may be supplied from the core particle to the roots of the SWT and the tubes grow longer, maintaining hollow capped tips. Addition of carbon atoms (and dimers) from the gas phase to the tips of the tubes may also help the growth of the tubes.

Seraphin and $\mathrm{Zhou}^{73}$ have reported the high-density preparation of SWT in the presence of mixed $\mathrm{Fe}-\mathrm{Ni}$ and $\mathrm{Fe}-\mathrm{Co}$ catalysts in an Ar atmosphere, found in the soot as well as in the weblike deposits formed in the chamber. They obtained gram quantities of SWT ranging from 0.9 to $3.1 \mathrm{~nm}$ in diameter and over $5 \mathrm{~mm}$ long. The tubes are arranged in bundles of 5 to 15 units. The density of tubes is much higher when using mixed $\mathrm{Fe}-\mathrm{Ni}$ and $\mathrm{Fe}-\mathrm{Co}$ catalysts instead of pure $\mathrm{Fe}$, $\mathrm{Co}$ or Ni. These authors point out that the observed $\mathrm{Fe}(\mathrm{Fe}-\mathrm{Ni})$ metal and carbide particles $(5-30 \mathrm{~nm})$ have a diameter much larger than that of the tubes and that no particles are associated with the tube tips, showing that the SWT do not grow out of the metal particles as in the pyrolysis methods. These authors believe that in the SWT growth the metals play a catalytic role on the atomic level, rather than just acting as heterogeneous nucleation sites.

Zhou et $a .^{74}$ have reported the observation of nonconcentric growth phenomena of carbon nanotubes during the arc-discharge evaporation without catalyst. This suggests that the driving force for the nucleation process is not always lined up with the center of the tube. Interestingly, when using

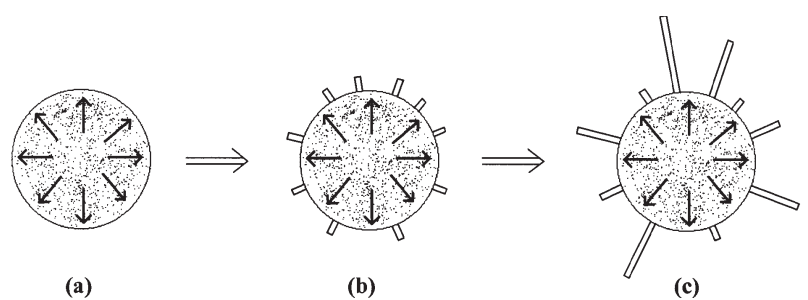

Fig. 3 Hypothetical growth process of carbon SWT from a metalcarbon alloy particle: (a) segregation of carbon towards the surface; (b) nucleation of SWT on the particle surface; $(c)$ growth of the SWT (adapted from Fig. 13 in ref. 68) 
$\mathrm{YC}_{2}$ as the catalyst, these researchers have also observed bundles of SWT growing out radially from the carbide particles.

Maiti et ll $^{75}$ have used molecular-dynamics simulations and total-energy calculations in order to analyse the growth mode in which the metal particles are much larger than the tube diameter, leading to the precipitation of a large number of SWT from a single particle surface. ${ }^{69-72}$ The starting material is a large metal particle covered by graphene sheets. According to the model, carbon atoms precipitate from the metal particle, migrate to the tube base and deposit a net number of hexagons on the tube stem. The authors discuss the case where only carbon atoms precipitate from the metal particles but note that dimers and trimers do not qualitatively change the results. All simulations show that a precipitated atom forms a handle between a pair of nearest-neighbour carbon atoms. Thus each handle atom is twofold coordinated, flanked by threefold-coordinated carbon atoms, which were nearest neighbours in the absence of the handle. On a flat graphene sheet the handle does not have any preferential site and will thermally migrate on the hexagonal network until it reaches the tube base. Indeed, calculations show that the energy of a single handle is a minimum at the point of highest curvature, which is the region where the heptagons are located. Total-energy calculations show that a pair of handles prefer to be on the opposite sites of a heptagon. The addition of hexagons then occurs through a sequence of processes involving such a pair of handles. However, Maiti et al. ${ }^{75}$ point out that providing an atomistic picture of nanotube nucleation is more difficult. They have therefore combined molecular-dynamics simulations on the carbon system with a conjecture that the metal particle surface contains protrusions whose maximum height is within a few nanometers, the particle diameter being of the order of a few tens of nanometers. From the simulations it emerges that protrusions with a diameter small compared to the height can lead to SWT nucleation, while wider protrusions lead only to a strained graphene sheet and no nanotube growth. This would explain why all observed SWT are narrow. The increased production of SWT with specific mixed catalysts may be attributed to either (1) an enhancement in the precipitation of carbon atoms, (2) changes in the activation barrier for growth or (3) the formation of a large number of narrow protrusions.

\section{Laser vaporization}

Guo et al. ${ }^{76}$ have proposed an original method for synthesizing SWT in which a mixture of carbon and transition metal are vaporized by a laser impinging on a metal-graphite composite target. They point out that in contrast to the arc method, direct vaporization allows far greater control over growth condition, permits continuous operation and produces nanotubes in higher yield $(70-90 \%)$ and of better quality. Their SWT are all about $1 \mathrm{~nm}$ in diameter and are arranged in bundles (called ropes), with similar spacing between adjacent nanotubes. No amorphous coating of the tubes was observed. These authors investigated various mono- and bimetallic catalysts: Ni produced the greatest yield, followed by Co. Pt produced a very small number of tubes, while no tubes were observed with $\mathrm{Cu}$ or $\mathrm{Nb}$ alone. For bimetallic catalysts, Co-Ni and Co-Pt mixtures yielded SWT in similarly high abundance, with a SWT yield 10-100 times that for single metals alone. These were closely followed by Ni-Pt, while a $\mathrm{Co}-\mathrm{Cu}$ mixture produced a small quantity of SWT. In all cases, no MWT were observed. No correlation was observed between SWT diameter and catalytic particle size. Guo et al. ${ }^{76}$ assumed that SWT originate from metal particles whose diameters were too small to nucleate and grow the second wall. They pointed out that no mechanism for SWT formation explains how metal particles are prevented from getting too big. Compared with the condensation of pure carbon vapour in the laser vaporization apparatus, which is known to produce $\mathrm{C}_{60}$ and other small spheroidal fullerenes, ${ }^{77}$ the presence of $c a .1 \%$ of metal atoms in the vapour produces dramatic changes. In the so-called 'scooter' mechanism, Guo et al. ${ }^{76}$ propose that before the fullerene precursor closes, a few metal atoms (perhaps only one) chemisorb on the carbon cluster and migrate to the dangling bonds at the carbon cluster edge, inhibiting closure of the fullerene by partially satisfying the previously dangling bonds. Carbon that now collides with a metal-carbon cluster will diffuse to its most energetically stable site, inserting between the carbon edges and the metal particle, lengthening the fullerene. Metal atoms that collide will also diffuse and add to the growing metal particle. However, collisions between metal clusters are inhibited by the presence of growing nanotubes attached to them. Thus, this may quench the metal particle size at 100 300 atoms to form the required 1-2 $\mathrm{nm}$ diameter catalytic particles. These authors note that continued growth of the SWT will still be favoured even when the metal particle at its tip grows beyond the initial 1-2 $\mathrm{nm}$ diameter. According to Guo et al. ${ }^{76}$ the observed enhancement in yield from the bimetallic catalysts compared with either metal alone strongly suggest that formation of SWT in all cases involves more than just a few metal atoms decorating the nanotube edge. These authors suggest that the principal effect of a mixture is to increase the mobility of carbon on and/or within the metal particle, resulting in a greater rate of SWT precipitation from the particle. The laser vaporization method was improved and the scooter mechanism refined in a subsequent work by the same group of authors. ${ }^{66}$

\section{Catalysis Methods}

Basically the catalysis methods consist in passing a gaseous flow containing a certain proportion of hydrocarbon (mostly $\mathrm{CH}_{4}, \mathrm{C}_{2} \mathrm{H}_{2}, \mathrm{C}_{2} \mathrm{H}_{4}$ and $\mathrm{C}_{6} \mathrm{H}_{6}$, usually as a mixture with $\mathrm{H}_{2}$ ) or $\mathrm{CO}$ over small transition metal particles. The formation of carbon filaments by catalytic decomposition of carbonaceous gases on metal particles has been known for a long time ${ }^{78}$ and the formation mechanisms have been hotly debated over the years. Many parameters, including the temperature and duration of the treatment, the gas composition and flow rate and the catalyst nature and size, will affect the nature of the carbon species in the resulting material. Indeed, one may obtain a mixture of amorphous carbon, carbon particles either connected or not to the metal or carbide particles, bulk or surface carbidic carbon, filaments that are not tubular (fibres) and various kinds of tubes including Iijima-type nanotubes. Rodrigue $\mathrm{z}^{79}$ has reviewed the advances in the development of these nanostructures, notably in the light of the progress made in electron microscopy techniques. It is notably stressed in this work $^{79}$ that active species for filament and nanotube formation are metals and not carbides. For the preparation of Iijima-type carbon nanotubes, on which we will focus in the following, it is of utmost importance to use metal particles in the nanometer size range. Achieving this is obviously related to the way the catalyst material is prepared. Interestingly, carbon nanotubes prepared by hydrocarbon decomposition are much longer (some tens or hundreds of micrometers) than those obtained by arc discharge (a few micrometers).

\section{Pyrolysis of hydrocarbons}

The investigations reviewed by Rodriguez ${ }^{79}$ usually concern materials prepared by impregnating a suitable substrate (graphite, $\mathrm{Al}_{2} \mathrm{O}_{3}, \mathrm{SiO}_{2}, \ldots$ ) with a salt of the desired metallic catalyst. A treatment in the appropriate atmosphere gives rise to metallic particles with a fairly broad size distribution. In consequence, these methods lack in selectivity with respect to SWT and MWT synthesis. 
Baker and Rodriguez ${ }^{80}$ have prepared carbon nanofibres and nanotubes by heat-treating $\mathrm{Fe}$ powder and $\mathrm{Fe}$ nanoparticles supported on carbon, respectively, in $\mathrm{C}_{2} \mathrm{H}_{4}-\mathrm{CO}-\mathrm{He}$ gas mixtures (at $600^{\circ} \mathrm{C}$ ). It is emphasized that nanofibres are obtained from large Fe particles $(>20 \mathrm{~nm})$ whereas nanotubes are formed with the aid of smaller particles $(<20 \mathrm{~nm})$. The catalyst particles are found at the tube tips and no amorphous carbon is deposited because of the relatively low temperature used. Interestingly, earlier work by the group of Baker ${ }^{81}$ had shown that the linear filament growth rate varies inversely with the mean radius of the catalytic particle. These authors ${ }^{80,82}$ have proposed a mechanism for filament formation involving the following steps: (1) gas adsorption at the metal surface followed by decomposition reactions leading to chemisorbed carbon species, (2) dissolution in and diffusion of carbon species through the metal particle to active growth areas, (3) precipitation of the carbon species to form the body of the filament and (4) migration of carbon species remaining on the metal surface around the particle to form the skin component of the filament. This mechanism accounts for the observation that carbon grows at the rear of the metal particle, which is carried away from the substrate surface. The crystallographic arrangement adopted by the metal particle will determine the direction in which the graphite platelets are oriented: parallel to the growth direction as in Iijima-type NT (nanotube), perpendicular to the growth direction (nontubular fibre) or in the so-called fishbone conformation (hollow fibre).

In a study of carbon fibres prepared by the pyrolysis of a $\mathrm{H}_{2}-\mathrm{C}_{6} \mathrm{H}_{6}$ mixture on $\mathrm{Fe}$, Oberlin et al. ${ }^{83}$ have reported that the filaments have various external shapes and contain a hollow tube with a diameter ranging from 2 to more than 50 $\mathrm{nm}$. They identified that the core regions are primarily formed by a catalytic effect, whereas the external regions correspond to a pyrolytic deposit. The thickness of this deposit decreased with the decrease in $\mathrm{C}_{6} \mathrm{H}_{6}$ proportion and treatment time. Very small $\mathrm{Fe}_{3} \mathrm{C}$ particles were found at the tip of the central tube of each fibre. These authors ${ }^{83}$ proposed a growth model related to the surface diffusion of carbon species on the catalyst particle (Fig. 4). An association of metal and hydrocarbon nucleates and diffuses on the clean Fe particle surface (which they assume is 'liquid-like') and eventually dissociates at the contact angle between the particle and the substrate, thus producing the beginning of a carbon shell. New metalhydrocarbon species dissociate on its edge and the carbon layers develop by lateral growth, following the external surface of the catalyst. Such a lateral growth exerts a force strong enough to lift up the catalyst particle above the surface of the substrate. The hollow channel in the centre is due to the fact that no carbon supply can reach the back of the particle. Growth of carbon layers would continue as long as there is a supply of metal from the top of the particle, the metal being progressively trapped between the carbon layers.

The model for filament morphology proposed by Tibbetts ${ }^{84}$ assumes that molecular decomposition and carbon solution occur at one side of a catalytic particle. This particle becomes supersaturated and the consequent gradient in chemical potential causes bulk diffusion to the back face of the particle where precipitation occurs (Fig. 5). Because the free energy of the (0001) basal plane of graphite is exceptionally low, it is energetically favourable for the fibre to precipitate with graphite basal planes parallel to the exterior planes and a hollow core. Calculated inner diameters were in good quantitative agreement with TEM observations.

Benissad et al. ${ }^{85-88}$ have studied the decomposition of $\mathrm{H}_{2}-\mathrm{CH}_{4}$ mixtures on graphite foils impregnated with $\mathrm{Fe}$ salts (nitrate, sulfate, ...). Their results generally support the conclusions of Baker et al., ${ }^{80,81}$ Oberlin et al. ${ }^{83}$ and Tibbetts. ${ }^{84}$ These authors ${ }^{85-88}$ propose that the catalytic nanoparticle active for nanotube growth is in the molten state and point (a)

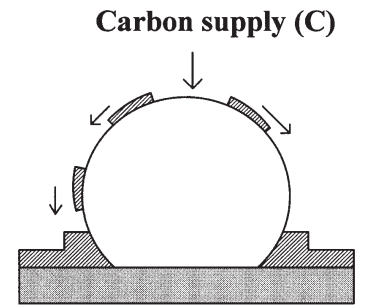

Substrate

(b)



(c)

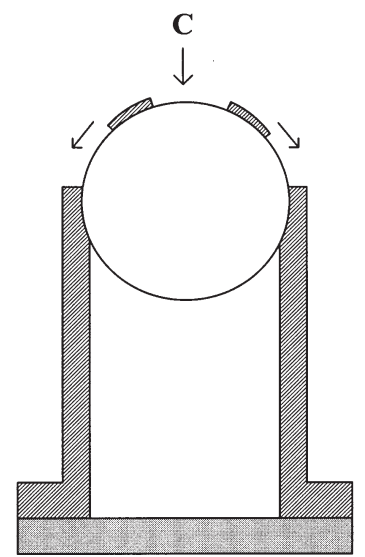

Fig. 4 Schematic illustration of tubular filament growth by a catalytic effect: $(a)$ an association of metal and hydrocarbon nucleates and diffuses on the clean Fe particle surface and eventually dissociates at the contact angle between the particle and the substrate; $(b)$ the beginning of a carbon shell; $(c)$ a new metal-hydrocarbon species dissociates on its edge and the carbon layers develop by lateral growth following the external surface of the catalyst, thus exerting a force strong enough to lift up the catalyst particle above the surface of the substrate (adapted from Fig. 21 in ref. 83)

out that tube lengthening takes place within very short times (seconds). José-Yacaman et al. ${ }^{89}$ also reported the synthesis of MWT by decomposition of $\mathrm{C}_{2} \mathrm{H}_{2}$ on Fe-impregnated graphite.

Most of the work presented above in this section was performed before the discovery of fullerenes and carbon nanotubes and therefore, although the formation of tubular carbon structures by a catalytic process was identified, did not concentrate on the preparation of Iijima-type SWT and MWT preferentially to other carbon species. More recent studies aim to achieve this, notably by using the smallest possible metal particles.

Ivanov et al. ${ }^{90}$ have prepared carbon nanotubes by the decomposition of $\mathrm{C}_{2} \mathrm{H}_{2}$ (and 1:4 $\mathrm{H}_{2}-\mathrm{C}_{2} \mathrm{H}_{2}$ ) on well-dispersed metal ( $\mathrm{Fe}, \mathrm{Co}, \mathrm{Ni}, \mathrm{Cu})$ particles strongly adsorbed on a support (graphite flakes, $\mathrm{SiO}_{2}$ ). Using $\mathrm{Fe}$ or $\mathrm{Co}$ as the catalyst, most of the filaments were graphitic and sometimes covered by amorphous carbon, whereas use of $\mathrm{Ni}$ or $\mathrm{Cu}$ leads to much more amorphous materials. $\mathrm{Co}-\mathrm{SiO}_{2}$ was found to be the best catalyst-support combination for the production of MWT. Straight and coiled tubes were obtained with inner and outer diameters of 3-7 and 15-20 nm, respectively, and up to $30 \mu \mathrm{m}$ 


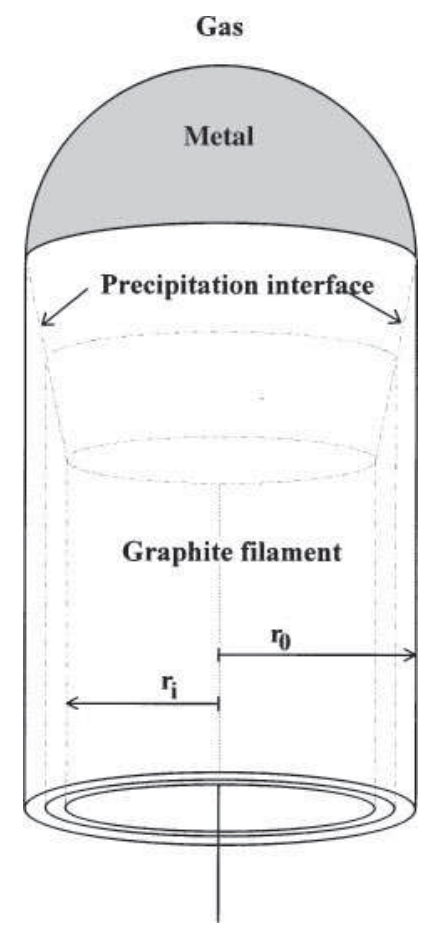

Fig. 5 Model for the formation of tubular filaments, showing the inner and outer diameters and the precipitation interface (adapted from Fig. 2 in ref. 84)

in length. Both the outer diameter and the thickness of the tubes depend on the size of the metal particle. However, no metal particles were found at the tube tips, indicating a difference in growth mechanism compared with those previously postulated. ${ }^{80-88}$ These researchers ${ }^{90}$ have optimized the method for catalyst preparation and the reaction conditions. The method of precipitation-ion-exchange was found to provide a better dispersion of metals on $\mathrm{SiO}_{2}$ than the impregnation technique. In addition, it is reported that a decrease of the treatment temperature (from 700 to $600{ }^{\circ} \mathrm{C}$ ) leads to a strong decrease in the amorphous carbon production, but also to a lesser degree of crystallinity of the tubes. Interestingly, further heating of the specimens in a $\mathrm{H}_{2}-\mathrm{N}_{2}$ atmosphere is claimed to result in the gasification of the amorphous carbon, leading to the cleaning of the MWT.
Moreover, a decrease in the contact time at constant temperature leads to the predominance of graphitization over pyrolysis. Length was also found to depend on the duration of the catalytic process, in agreement with José-Yacaman et al. ${ }^{89}$ However, it is pointed out that the longest tubes are also the thickest. Further work by the same group of authors ${ }^{91-93}$ stresses that both the selectivity and the yield of the catalytic method are significantly higher than that of the arc-discharge method with respect to MWT formation. An improvement was proposed by these researchers, ${ }^{92,93}$ which consists in the use of a zeolite-supported Co catalyst, resulting in very finely dispersed metal particles $(1-50 \mathrm{~nm}$ in size). Only on this catalyst could these workers observe extremely thin tubes $(4 \mathrm{~nm})$ with the walls composed of 2-3 layers. Their amount is, however, very small. Interestingly, it is proposed ${ }^{92}$ that a Co carbide, and not $\mathrm{Co}$, is the active catalyst for the production of nanotubes. This group has proposed growth mechanisms for coiled $^{94}$ and helix-shaped ${ }^{95}$ carbon nanotubes. It is claimed $^{95}$ that the distinction between mechanisms, whereby the catalytic particle promotes 'tip growth' or 'base growth', does not appear to be essential because in both cases the tube grows away from the particle by the deposition of carbon in the contact region between the particle and the already formed tube segment. Whether the carbon diffuses through the particle before precipitating at the surface of the particle or is formed directly from the gas phase at the surface area in contact with the tube is also not essential for the geometry of the process. The different growth stages of MWT are shown in Fig. $6 .^{95}$ The concept of a spatial-velocity hodograph is introduced to describe quantitatively the extrusion of a carbon tubule from a catalytic particle. ${ }^{95}$

The present authors have proposed another method aimed at obtaining metal particles at the size required for Iijima-type carbon nanotubes. Indeed, earlier works have shown that metal oxide nanocomposite powders are advantageously prepared by selective reduction in $\mathrm{H}_{2}$ of oxide solid solutions. ${ }^{96-105}$ In these materials, the metal particles $(\mathrm{Cr}, \mathrm{Fe}, \mathrm{Co}$, $\mathrm{Ni}$ and their alloys) are generally smaller than $10 \mathrm{~nm}$ in diameter and are located both inside and at the surface of the matrix grains $\left(\mathrm{Al}_{2} \mathrm{O}_{3}, \mathrm{Cr}_{2} \mathrm{O}_{3}, \mathrm{MgO}, \mathrm{MgAl}_{2} \mathrm{O}_{4}\right)$. It has been shown ${ }^{106}$ that when using a $\mathrm{H}_{2}-\mathrm{CH}_{4}$ gas mixture instead of pure $\mathrm{H}_{2}$ for the reduction of an $\alpha-\mathrm{Al}_{1.9} \mathrm{Fe}_{0.1} \mathrm{O}_{3}$ solid solution, the pristine $\mathrm{Fe}$ nanoparticles formed in situ, upon reduction of the very homogeneously dispersed surface $\mathrm{Fe}^{3+}$ ions, are active at a size adequate for the catalytic formation of nano- (a)

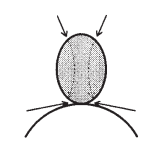

(b)

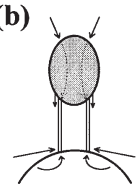

(c)

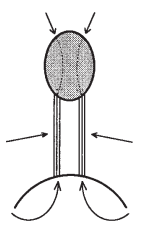

(d)

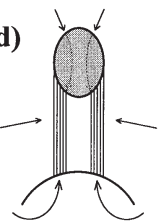

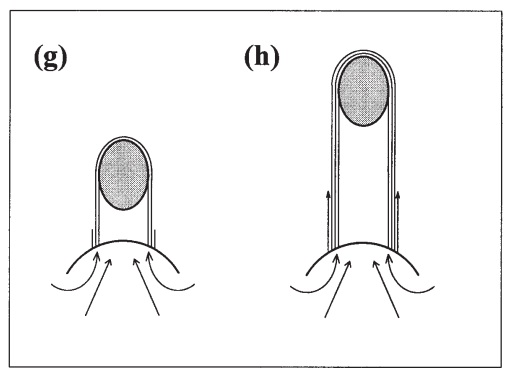

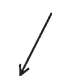

(e)



(f)

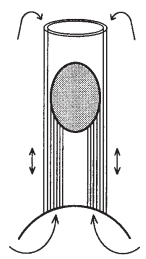

Fig. 6 Growth stages of carbon MWT: $(a)$ a small catalytic particle rests on a larger one that acts as a support; $(b)$ and $(c)$ the small particle is lifted away from the support by the deposition of graphene sheets, formed from carbon diffusion through the catalyst and through the base; $(d)$ the outer diameter of the tube becomes equal to the particle size; $(e)$ a layer of graphite covers the small particle and inhibits further tip growth of the tube; $(f)$ tubular layers fed by the supporting particle grow beyond the small particle; $(g)$ and $(h)$ the particle is already covered by a graphite layer during the initial stage; further growth occurs by extrusion through the base and diffusion occurs along the graphite surface (adapted from Fig. 4 in ref. 95) 
tubes. The resulting carbon nanotube- $\mathrm{Fe}-\mathrm{Al}_{2} \mathrm{O}_{3}$ composite powder contains an enormous amount of SWT and MWT with a diameter in the $1.5-15 \mathrm{~nm}$ range (Fig. 1). Most MWT appear to have only 2 or 3 shells. The nanotubes are arranged in bundles smaller than $100 \mathrm{~nm}$ in diameter and which may be up to $100 \mu \mathrm{m}$ long. The bundles appear to be very flexible (Fig. 7). We have proposed ${ }^{106}$ a method based on chemical analysis and specific surface area measurements that allows a quantification of the amount of nanotubes in the composite powder and also produces a so-called quality value, a high quality denoting a smaller average tube diameter and/or more carbon in tubular form. It has been calculated that the total bundle length in $1 \mathrm{~g}$ of composite powder is greater than $100000 \mathrm{~km}$. Indeed, the metal oxide grains are uniformly covered by a weblike network of bundles (Fig. 8) and the powder is so densely agglomerated that it retains the shape of the reduction vessel when transferred to a storage box. Further work ${ }^{107,108}$ on the $\mathrm{Fe}-\mathrm{Al}_{2} \mathrm{O}_{3}$ system has confirmed that only the smallest $\mathrm{Fe}$ nanoparticles (probably $<5 \mathrm{~nm}$ ), resulting from the reduction of a stable $\alpha-\mathrm{Al}_{2} \mathrm{O}_{3}$-rich solid solution $\left(\alpha-\mathrm{Al}_{2-2 x} \mathrm{Fe}_{2 x} \mathrm{O}_{3}, 0<x \leqslant 0.1\right)$, are active for the formation of Iijima-type tubes. However, it is difficult to establish clearly that there is a connection between such a particle and a nanotube. In contrast, larger Fe particles formed upon the reduction of a $\mathrm{Fe}_{2} \mathrm{O}_{3}$-rich solid solution give rise to thick carbon filaments and are more prone to the formation of inactive carbide $\left(\mathrm{Fe}_{3} \mathrm{C}\right)$, on the one hand, and to be poisoned by a thick carbon coating, on the other hand. In addition, for a given $\mathrm{Fe}$ content ( $\leqslant 10 \%$ cationic), increasing the reduction temperature favours the quantity of nanotubes because of a

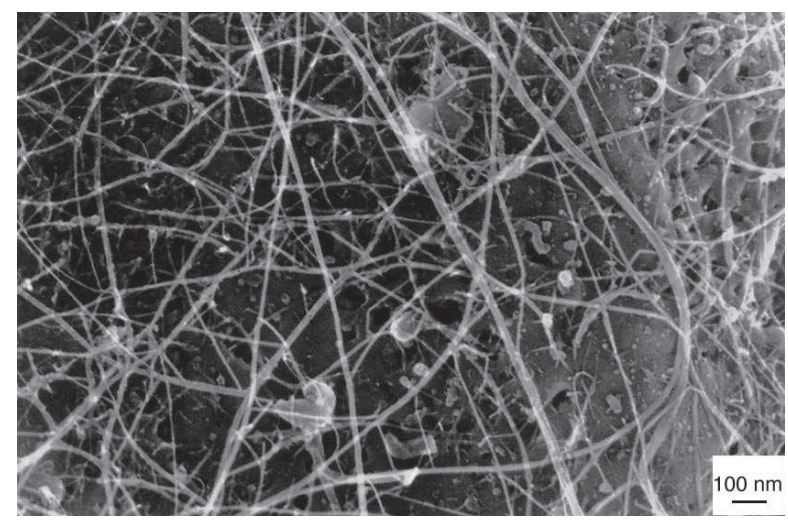

Fig. 7 Scanning electron microscopy image showing bundles of carbon nanotubes in a carbon nanotube- $\mathrm{Fe}-\mathrm{Al}_{2} \mathrm{O}_{3}$ composite powder

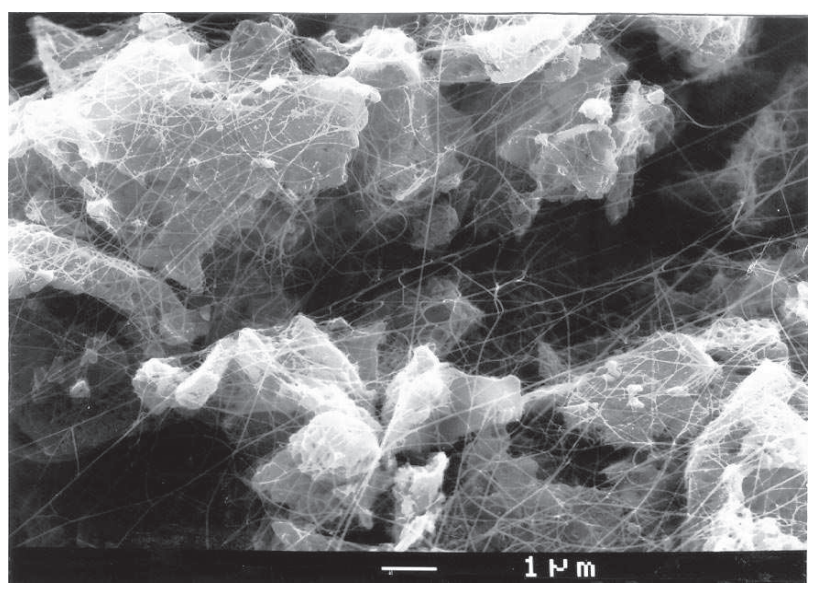

Fig. 8 Scanning electron microscopy image showing the weblike net of carbon nanotube bundles covering the $\mathrm{Fe}-\mathrm{Al}_{2} \mathrm{O}_{3}$ grains. Some bundles have been traced for $100 \mu \mathrm{m}$ higher $\mathrm{CH}_{4}$ supersaturation level in the gas atmosphere, but also provokes a decrease in carbon quality. ${ }^{107}$ Similar MWT have also been prepared using $\mathrm{M}-\mathrm{MgAl}_{2} \mathrm{O}_{4}(\mathrm{M}=\mathrm{Fe}, \mathrm{CO}$ or $\mathrm{Ni})^{109}$ and $\mathrm{M}-\mathrm{M}^{\prime}-\mathrm{MgAl}_{2} \mathrm{O}_{4}\left(\mathrm{M}, \mathrm{M}^{\prime}=\mathrm{Fe}, \mathrm{CO} \text { or } \mathrm{Ni}\right)^{110}$ powders as catalysts. $\mathrm{Co}$ and $\mathrm{Fe}_{0.5} \mathrm{Co}_{0.5}$ nanoparticles give the best results with respect to both the quantity and quality of nanotubes, but interestingly the three single metals ( $\mathrm{Fe}, \mathrm{Co}$, $\mathrm{Ni}$ ) and all of their studied alloys were found to produce carbon nanotubes to a certain extent.

\section{CO disproportionation}

Herreyre and Gadelle ${ }^{111}$ have prepared carbon nanotubes by $\mathrm{CO}$ disproportionation catalysed by $\mathrm{Fe}-\mathrm{Co}(50 \mathrm{wt} . \% \mathrm{Co})$ particles produced by in situ reduction of a mixture of the corresponding nitrates. The tube diameters (average value equal to $25 \mathrm{~nm}$ ) correspond to the size of the catalytic particle found attached to the tube end. Tube length is of the order of $2 \mu \mathrm{m}$. These authors investigated the influence of the presence of small quantities of $\mathrm{H}_{2}$ in the reducing atmosphere and observed that $\mathrm{H}_{2}$ was not essential for nanotube formation, in contrast to results obtained using non-alloyed metals $(\mathrm{Fe}, \mathrm{Co}$, $\mathrm{Ni}){ }^{112}$

Dai et al. ${ }^{113}$ have prepared isolated SWT by CO diproportionation catalyzed by Mo particles a few nanometers in size. The tube diameters, ranging from 1 to $5 \mathrm{~nm}$, are closely correlated with the size of the catalytic particle found attached to the tube end. These results represent the first experimental evidence of SWT produced by preformed catalytic particles. This is in contrast with the observations of SWT formed by the arc-discharge and laser-vaporization processes in which no relation was found between metal particles and SWT. The tubes have a length ranging between $c a .100 \mathrm{~nm}$ and several micrometers and are free of the amorphous carbon coating typically observed in catalytically produced MWT. Thus, these authors ${ }^{113}$ have proposed a mechanism wholly different from those proposed ${ }^{55-60,64,68,69,75,76}$ for the catalytic formation of SWT by arc discharge and laser vaporization and from those reported ${ }^{80-88,94,95}$ for the catalytic formation of MWT. A nanometric metal particle contains a very high fraction of surface atoms and the surface energy per atom is very high. An excess of carbon assembles on the metal particle surface to form a graphene cap (the so-called yarmulke) with its edges strongly chemisorbed to the metal. Since the basal plane of graphite has an extremely low surface energy, the total surface energy diminishes. Newly arriving carbon will continue to assemble on the surface of the catalyst. There are three places for additional carbon to go. (1) The original surface shell can continue to grow around the particle, which ultimately results in the overcoating and deactivation of the catalyst. (2) A second cap can form underneath the first, spaced by roughly the interspacing of graphite. As additional caps form, older caps are forced to lift up by forming a cylindrical tube whose open end remains chemisorbed onto the catalytic particle. (3) Carbon can add to the cylindrical section of a growing layer. A crucial feature of the yarmulke mechanism is the avoidance at all stages of growth of any open edge, which would expose energetically costly dangling bonds. It also provides an automatic solution to forming caps and tubes that have no seams. Dai et al. ${ }^{113}$ observed that their larger Mo particles were fully covered by graphite and were thus inactive for tube catalysis. Thus, obtaining SWT only is related to the very small size of the Mo particles, but it is noted that the reasons for the production of particles with such a size distribution are not fully understood.

\section{Pyrolysis of metallocenes}

Song et al. ${ }^{14,115}$ have reported on the formation of carbon nanotubes by the decomposition of ferrocene, which acts as a feedstock for both the transition metal and carbon, in a silica aerogel. They observed short MWT (some tens of nanometers) 
coated with amorphous carbon and sometimes containing what was thought to be an Fe oxide impurity. Onion-like species were observed as well. These workers ${ }^{115}$ proposed a model based on that of Zhang et al. ${ }^{4}$. Sen et al. ${ }^{116}$ have also investigated the pyrolysis of metallocenes (ferrocene, cobaltocene and nickelocene) and metallocene- $\mathrm{C}_{6} \mathrm{H}_{6}$ mixtures in an $\mathrm{Ar}-\mathrm{H}_{2}$ stream. The obtained MWT are filled with the corresponding metal particles and are coated with a pyrolytic carbon deposit. Their results support the yarmulke mechanism. ${ }^{113}$

\section{Conclusions}

Several mechanisms have been proposed to account for the nucleation and growth of single-wall and multiwall carbon nanotubes in the presence of highly divided metals. Some mechanisms involve a metal, or a metal-carbon combination, at the atomic or cluster level, while others deal with preformed nanometric metal (or metal-carbon) particles of the smallest possible size (probably down to $1-2 \mathrm{~nm}$ ). The role of the nature of the metal or alloy is as yet very confused, many contradictory results having been reported. Most synthesis methods suffer from a lack of selectivity between the different forms of carbon obtained, partly because the catalyst itself lacks size homogeneity. Also, the nucleation and lengthening processes have to compete with side reactions and all appear to be extremely quick in the appropriate conditions, which may be reached simultaneously in different parts of the specimen. In most cases, a compromise has to be found between the quality of the nanotubes obtained and the yield. Thus the use of carbon nanotubes as parts of novel nanocomposite materials that may benefit from their exceptional properties is still in its infancy.

\section{References}

1 T. W. Ebbesen, Annu. Rev. Mater. Sci., 1994, 24, 235.

2 S. Iijima, Nature (London), 1991, 354, 56.

3 H. W. Kroto, J. R. Heath, S. C. O'Brien, R. F. Curl and R. E. Smalley, Nature (London), 1985, 318, 162.

4 X. F. Zhang, X. B. Zhang, G. Van Tendeloo, S. Amelinckx, M. Op De Beeck and J. Van Landuyt, J. Cryst. Growth, 1993, 130, 368.

5 P. J. Harris, Eur. Microsc. Anal., 1994, 9, 13.

6 G. Hu, X. F. Zhang, D. P. Yu, S. Q. Feng, W. Xu and Z. Zhang, Solid State Commun., 1996, 98, 547.

7 D. Ugarte, Microsc. Microanal. Microstruct., 1993, 4, 505.

8 L. A. Bursill, J. L. Peng and X. D. Fan, Philos. Mag. A, 1995, 71, 1161 .

9 S. J. Tans, M. H. Devoret, H. Dai, A. Thess, R. E. Smalley, L. J. Geerligs and C. Dekker, Nature (London), 1997, 386, 474.

10 A. Y. Kasumov, I. I. Khodos, P. M. Ajayan and C. Colliex, Europhys. Lett., 1996, 34, 429.

11 Y. Nakayama, S. Akita and Y. Shimada, Jpn. J. Appl. Phys., 1995, 34, L10.

12 H. Dai, E. W. Wong and C. M. Lieber, Science, 1996, 272, 523.

13 L. Langer, L. Stockman, J. P. Heremans, V. Bayot, C. H. Olk, C. Van Haesendonck, Y. Bruynserade and J. P. Issi, J. Mater. Res., 1994, 9, 927.

14 X. K. Wang, R. P. H. Chang, A. Patashinski and J. B. Ketterson, J. Mater. Res., 1994, 9, 1578.

15 D. H. Robertson, D. W. Brenner and J. W. Mintmire, Phys. Rev. B, 1992, 45, 12592 .

16 W. A. De Heer, W. S. Bacsa, A. Chatelain, T. Gerfin, R. Humphrey-Baker, L. Forro and D. Ugarte, Science, 1995, 268, 845.

17 R. Seshadri, A. Govindaraj, H. N. Aiyer, R. Sen, G. N. Subbanna, A. R. Raju and C. N. R. Rao, Curr. Sci., 1994, 66, 839.

18 R. Seshadri, H. N. Aiyer, A. Govindaraj and C. N. R. Rao, Solid State Commun, 1994, 91, 195.

19 M. S. Dresselhaus, G. Dresselhaus and P. C. Eklund, Science of Fullerenes and Carbon Nanotubes, Academic Press, San Diego, 1995.

20 S. C. Tsang, P. J. F. Harris and M. L. H. Green, Nature (London), 1993, 362, 520.
21 P. M. Ajayan, T. W. Ebbesen, T. Ishihashi, S. Iijima, K. Tanigaki and H. Hiura, Nature (London), 1993, 362, 522.

22 P. M. Ajayan and S. Iijima, Nature (London), 1993, 361, 333.

23 S. C. Tsang, Y. K. Chen, P. J. F. Harris and M. L. H. Green, Nature (London), 1994, 372, 159.

24 P. M. Ajayan, C. Colliex, J. M. Lambert, P. Bernier, L. Barbedette, M. Tence and O. Stephan, Phys. Rev. Lett., 1994, 72, 1722.

25 Y. Murakami, T. Shibata, K. Okuyama, T. Arai, H. Suematsu and Y. Yoshida, J. Phys. Chem. Solids, 1993, 54, 1861.

26 C. Guerret-Piecourt, Y. Le Bouar, A. Loiseau and H. Pascard, Nature (London), 1994, 372, 761.

27 A. Loiseau and H. Pascard, Chem. Phys. Lett., 1995, 256, 246.

28 S. Subramoney, R. S. Ruoff, D. C. Lorents, B. Chan, R. Malhotra, M. J. Dyer and K. Parvin, Carbon, 1994, 32, 507.

29 P. M. Ajayan, O. Stephan, Ph. Redlich and C. Colliex, Nature (London), 1995, 375, 564

30 E. Dujardin, T. W. Ebbesen, H. Hiura and K. Tanigaki, Science, 1994, 265, 1850.

31 T. W. Ebbesen, J. Phys. Chem. Solids, 1996, 57, 951.

32 B. C. Satishkumar, A. Govindaraj, E. M. Vogl, L. Basumallik and C. N. R. Rao, J. Mater. Res., 1997, 12, 604.

33 P. Calvert, Nature (London), 1992, 357, 365

34 P. M. Ajayan, O. Stephan, C. Colliex and D. Trauth, Science, 1994, 265, 1212.

35 R. S. Ruoff and D. C. Lorents, Carbon, 1995, 33, 925.

36 S. B. Sinnott, C. T. White and D. W. Brenner, Mater. Res. Soc. Symp. Proc., 1995, 359, 241.

37 S. Iijima, Ch. Brabec, A. Maiti and J. Bernholc, J. Phys. Chem., 1996, 104, 2089.

38 M. M. J. Treacy, T. W. Ebbesen and J. M. Gibson, Nature (London), 1996, 381, 678.

39 J. F. Despres, E. Daguerre and K. Lafdi, Carbon, 1995, 33, 87.

40 M. R. Falvo, G. J. Clary, R. M. Taylor III, V. Chi, F. P. Brooks Jr, S. Washburn and R. Superfine, Nature (London), 1997, 389, 582.

41 N. Hamada, S. Sawada and A. Oshiyama, Phys. Rev. Lett., 1992, 68, 1579.

42 J. W. Mintmire, B. I. Dunlap and C. T. White, Phys. Rev. Lett., $1992,68,631$.

43 T. W. Ebbesen, H. J. Lezec, H. Hiura, J. W. Bennett, H. F. Ghaemi and T. Thio, Nature (London), 1996, 382, 54.

44 T. W. Ebbesen, P. M. Ajayan, H. Hiura and K. Tanigaki, Nature (London), 1992, 367, 519.

45 E. V. Barrera, J. Sims, D. L. Callahan, V. Provenzano, J. Milliken and R. L. Holtz, J. Mater. Res., 1994, 9, 2662.

46 H. Dai, J. H. Hafner, A. G. Rinzler, D. T. Colbert and R. E. Smalley, Nature (London), 1996, 384, 147.

47 W. B. Downs and R. T. K. Baker, J. Mater. Res., 1995, 10, 625.

48 N. Rodriguez, M. S. Kim and R. T. K. Baker, J. Phys. Chem., 1994, 98, 13108.

49 W. A. De Heer, A. Chatelain and D. Ugarte, Science, 1995, 270, 1179 .

50 N. A. Kiselev, O. I. Lebedev, A. N. Kiselev, V. I. Bondarenko, L. A. Chernozatonskii, Z. J. Kosakovskaja, O. E. Omelianovski, V. I. Tzebro and E. A. Fedorov, Inst. Phys. Conf. Ser., 1995, 146, 65.

51 M. Terrones, N. Grobert, J. Olivares, J. P. Zhang, H. Terrones, K. Kordatos, W. K. Hsu, J. P. Hare, P. D. Townsend, K. Prassides, A. K. Cheetham, H. W. Kroto and D. R. M. Walton, Nature (London), 1997, 388, 52.

52 Ch. Laurent, A. Peigney, O. Quénard and A. Rousset, Key Eng. Mater., 1997, 132-136, 157; Ch. Laurent, A. Peigney, O. Dumortier and A. Rousset, J. Eur. Ceram. Soc., 1998, in press.

53 T. W. Ebbesen and P. M. Ajayan, Nature (London), 1992, 358, 220.

54 C. H. Kiang, W. A. Goddard, R. Beyers, J. R. Salem and D. Bethune, J. Phys. Chem. Solids, 1996, 57, 35.

55 R. Saito, G. Dresselhaus and M. S. Dresselhaus, Appl. Phys. Lett., 1992, 60, 2204

56 M. Endo and H. W. Kroto, J. Phys. Chem., 1992, 96, 6941.

57 S. Iijima P. M. Ajayan and T. Ichihashi, Phys. Rev. Lett., 1992, 69, 3100.

58 S. Iijima and T. Ichihashi, Nature (London), 1993, 363, 603.

59 S. Iijima, Mater. Sci. Eng., 1993, B19, 172.

60 R. E. Smalley, Mater. Sci. Eng., 1993, B19, 1

61 D. S. Bethune, C. H. Kiang, M. S. de Vries, G. Gorman, R. Savoy, J. Vazquez and R. Beyers, Nature (London), 1993, 363, 605.

62 R. T. K. Baker and P. S. Harris, in Chemistry and Physics of Carbon, eds. P. I. Walker, Jr and P. A. Thrower, Marcel Dekker, New York, 1978, vol. 14, pp. 83-165.

63 M. S. Kim, N. M. Rodriguez and R. T. K. Baker, J. Catal., 1991, 131, 60 . 
64 C. H. Kiang and W. A. Goddard, Phys. Rev. Lett., 1996, 76, 2515.

65 C. Journet, W. K. Maser, P. Bernier, A. Loiseau, M. Lamy de la Chapelle, S. Lefrant, P. Deniard, R. Lee and J. E. Fisher, Nature (London), 1997, 388, 756

66 A. Thess, R. Lee, P. Nikolaev, H. Dai, P. Petit, J. Robert, D. T. Colbert, C. Xu, Y. H. Lee, S. G. Kim, A. G. Rinzler, G. E. Scuseria, D. Tomanek, J. E. Fisher and R. E. Smalley, Science, 1996, 273, 483.

67 Y. Saito, T. Yoshikawa, M. Okuda, N. Fujimoto, K. Sumiyama, K. Suzuki, A. Kasuya and Y. Nishina, J. Phys. Chem. Solids, 1993, 54, 1849.

68 Y. Saito, Carbon, 1995, 33, 979.

69 Y. Saito, M. Okuda, N. Fujimoto, T. Yoshikawa, M. Tomita and T. Hayashi, Jpn. J. Appl. Phys. 2, 1994, 33, L526.

70 Y. Saito, in Recent Advances in the Chemistry and Physics of Fullerenes and Related Materials, ed. K. M Kadish and R. S. Ruoff, Electrochemical Society, Pennington, 1994.

71 S. Subramoney, R. S. Ruoff, D. C. Lorents and R. Malhotra, Nature (London), 1993, 366, 637.

72 D. Zhou, S. Seraphin and S. Wang, Appl. Phys. Lett., 1994, 65, 1593.

73 S. Seraphin and D. Zhou, Appl. Phys. Lett., 1994, 64, 2087.

74 D. Zhou, S. Seraphin and S. Wang, Mater. Res. Soc. Symp. Proc., 1994, 349, 257.

75 A. Maiti, C. J. Brabec and J. Bernholc, Phys. Rev. B, 1997, 55, 6097

76 T. Guo, P. Nikolaev, A. Thess, D. T. Colbert and R. E. Smalley, Chem. Phys. Lett., 1996, 260, 471.

77 R. E. Haufler, Y. Chai, L. P. F. Chibante, J. Conceicao, C. Jin, L.-S. Wang, S. Maruyama and R. E. Smalley, Mater. Res. Soc. Symp. Proc., 1991, 206, 627.

78 P. Schützenberger and L. Schützenberger, C. R. Séances Acad. Sci. (Paris), 1890, 111, 774.

79 N. M. Rodriguez, J. Mater. Res., 1993, 8, 3233.

80 R. T. K. Baker and N. M. Rodriguez, Mater. Res. Soc. Symp. Proc., 1994, 349, 251.

81 R. T. K. Baker, P. S. Harris, R. B. Thomas and R. J. Waite, J. Catal., 1973, 30, 86.

82 J. L. Figueiredo, C. A. Bernardo, J. J. Chludzinski Jr, R. T. K. Baker, J. Catal., 1988, 110, 127.

83 A. Oberlin, M. Endo and T. Koyama, J. Cryst. Growth, 1976, 32, 335.

84 G. G. Tibbetts, J. Cryst. Growth, 1984, 66, 632.

85 F. Benissad, P. Gadelle, M. Coulon and L. Bonnetain, Carbon, 1988, 26, 61.

86 F. Benissad, P. Gadelle, M. Coulon and L. Bonnetain, Carbon, 1988, 26, 425.

87 F. Benissad, P. Gadelle, M. Coulon and L. Bonnetain, Carbon, 1989, 27, 585.

88 F. Benissad and P. Gadelle, Carbon, 1993, 31, 21

89 M. José-Yacaman, M. Miki-Yoshida, L. Rendon and J. G. Santiesteban, Appl. Phys. Lett., 1993, 62, 657.

90 V. Ivanov, J. B. Nagy, Ph. Lambin, A. Lucas, X. B. Zhang, X. F. Zhang, D. Bernaerts, G. Van Tendeloo, S. Amelinckx and J. Van Landuyt, Chem. Phys. Lett., 1994, 223, 329.
91 K. Hernadi, A. Fonseca, J. B. Nagy, D. Bernaerts, J. Riga and A. Lucas, Synth. Metals, 1996, 77, 31.

92 V. Ivanov, A. Fonseca, J. B. Nagy, A. Lucas, P. Lambin, D. Bernaerts and X. B. Zhang, Carbon, 1995, 33, 1727.

93 K. Hernadi, A. Fonseca, J. B. Nagy, D. Bernaerts, A. Fudala and A. A. Lucas, Zeolites, 1996, 17, 416.

94 A. Fonseca, K. Hernadi, J. B. Nagy, Ph. Lambin and A. A. Lucas, Synth. Metals, 1996, 77, 235.

95 S. Amelinckx, X. B. Zhang, D. Bernaerts, X. F. Zhang, V. Ivanov and J. B. Nagy, Science, 1995, 267, 635.

96 X. Devaux, Ch. Laurent, M. Brieu and A. Rousset, J. Alloys Compd., 1992, 188, 179.

97 X. Devaux, Ch. Laurent and A. Rousset, Nanostruct. Mater., 1992, 2, 339 .

98 Ch. Laurent, Ch. Blaszczyk, M. Brieu and A. Rousset, Nanostruct. Mater., 1995, 6, 317.

99 Ch. Laurent and A. Rousset, Key Eng. Mater., 1995, 108-110, 405.

100 Ch. Laurent, A. Rousset, M. Verelst, K. R. Kannan, A. R. Raju and C. N. R. Rao, J. Mater. Chem., 1993, 3, 513.

101 M. Verelst, K. R. Kannan, G. N. Subbanna, C. N. R. Rao, Ch. Laurent and A. Rousset, J. Mater. Res., 1992, 7, 3072.

102 Ch. Laurent, J. J. Demai, A. Rousset, K. R. Kannan and C. N. R. Rao, J. Mater. Res., 1994, 9, 229.

103 O. Quénard, Ch. Laurent, M. Brieu and A. Rousset, Nanostruct. Mater., 1996, 7, 497.

104 O. Quénard, E. De Grave, Ch. Laurent and A. Rousset, J. Mater. Chem., 1997, 7, 2457.

105 V. Carles, M. Brieu and A. Rousset, Nanostruct. Mater., 1997, 8, 529.

106 A. Peigney, Ch. Laurent, F. Dobigeon and A. Rousset, J. Mater. Res., 1997, 12, 613

107 Ch. Laurent, A. Peigney and A. Rousset, J. Mater. Chem., 1998, 8, 1263.

108 Ch. Laurent, A. Peigney, O. Dumortier and A. Rousset, J. Eur. Ceram. Soc., 1998, in press.

109 A. Govindaraj, E. Flahaut, Ch. Laurent, A. Peigney, A. Rousset and C. N. R. Rao, J. Mater. Res., submitted.

110 E. Flahaut, A. Govindaraj, A. Peigney, Ch. Laurent, A. Rousset, C. N. R. Rao, unpublished work

111 S. Herreyre and P. Gadelle, Carbon, 1995, 33, 234.

112 G. A. Jablonski, F. W. Geurts, A. Sacco Jr and R. R. Biederman, Carbon, 1992, 30, 87

113 H. Dai, A. G. Rinzler, P. Nikolaev, A. Thess, D. T. Colbert and R. E. Smalley, Chem. Phys. Lett., 1996, 260, 471.

114 X. Y. Song, W. Cao and A. J. Hunt, Mater. Res. Soc. Symp. Proc., 1994, 349, 269.

115 X. Y. Song, W. Cao, M. R. Ayers and A. J. Hunt, J. Mater. Res., 1995, 10, 251.

116 R. Sen, A. Govindaraj and C. N. R. Rao, Chem. Phys. Lett., 1997, 267, 276 